\title{
The Intercultural Competence in Advertising Translation
}

\author{
Dr. Salian Çullhaj \\ German Department, University of Tirana, Faculty of Foreign Languages, Albania \\ Dr. Elvis Bramo \\ Greek Department, University of Tirana, Faculty of Foreign Languages, Albania
}

\begin{abstract}
In this article, we would like to examine one of the most difficult types of translation, namely the translation of advertising texts. Why one of the most difficult? Because it's not enough to master the source language for translating an advertising. Even if you can easily translate knotty technical instructions, it's doesn't guarantee that you will accurately render an advertising article into another language. The translator must be able to think creatively, and it is not so easy to learn. In addition, the purpose of the advertising translation is not just to transfer the meaning of words, but also to attract potential customers. No other text does attempt such a task.
\end{abstract}

Keywords: advertising, translation, cultural, slogan, competence, language, reader

\section{Introduction}

Learning a foreign language means learning a new culture, a new way of life, behavior, thinking, another logic, a different, a new one, means to enter into a mysterious world as first, to understand individual behavior, to argument the entire new information and knowledge.

Given this above-mentioned definition all the problems that can disturb us regarding foreign language, its implications, and difficulties in translation take shape immediately.

Let us focus on this work in the field of cross-cultural influences and the difficulties encountered in translating the advertising sector focusing on what advertising is and where is it intended.

Although advertising is a kaleidoscopic, simplified and distorting reflection of the society, to which it is addressed, it remains nevertheless a speech closest and most representative of the social perception compared with journalistic or political lecture. Free of ethical or political priorities, expression of the dominant discourse, it aims to be close to the target, which makes a speech particularly sensitive to social caricature. She finds inspiration in social clichés environment, templates and common places.

Translation of advertising is a actual media subject, located at the intersection of applied linguistics with pragmatics, and sociolinguistics and the translator not only need to translate, but must adapt the message in relation to language and above all to the culture of the country. For this reason it is essential that the interpreter has a background in communication, in order to find his place in the process of creating advertising.

In the case of the advertising of the same product, careful attention should be paid that the examples are not far-fetched, even misplaced. These can be failed examples, many of them mechanical adjustments from one version to another and may reflect lack of sensitivity towards the public the advertising is being addressed. All these defects can damage the persuasive force of advertising message and can not clearly reflect the cultural context of the language, in which the advertising is being translated.

In an advertisement, the slogan, is the most important unit, that constitutes the most difficult to translate as well. This swing between three positions: the seduction one, the technical information and the adaptation to the cultural context. 
A large number of advertising revolve around ideological stereotypes, which respond to public expectations. An

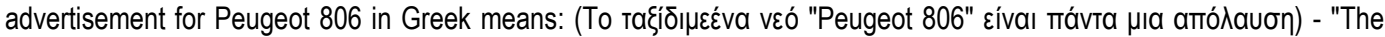
journey with the new Peugeot 806 is always a pleasure. " The same ad in the Albanian language comes: «Me Pëzhonë 806 më shumë kënaqësi dhe siguri». "With the new Peugeot 806 more pleasure and safety. " In contrast to the Greek version, the Albanian version is based on a mentality that expose safety to the Albanian community, while for the same advertisement in Greece the French Peugeot give more importance to comfort. - In the field of translation of advertising, the most important is the systematic adaptation toward the targeted communities, rather than linguistic conformity of the same advertising message.

The interpreter should consider the problem of loyalty to the concept of advertising, which is very interesting. - In advertising, language it is not simply a tool, so if you see it as such, you are in in danger of losing cultural identity. Literally translations should be avoided, in order not to make mistakes that can be considered "cultural", as noted in the advertisement of beer Amstel where we have a literally translation:

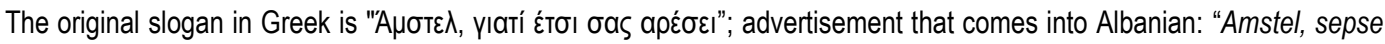
kështu ju pëlqen"; "Amstel, because this is how you like it," or the advertising of "Snikers" which in Greece lies with the

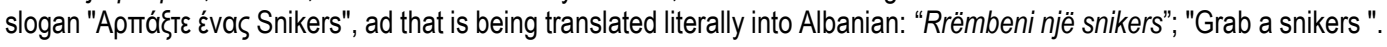

"Пávta Coca-Cola"; "Gjithmonë Coca-cola"; "Always Coca-Cola", this is another well-known ad throughout the world and here we can see the case how, the words are selected intentionally by promoters of this product such that the slogan in question be translatable into all languages of the world avoiding possible deviations from the original intention of the company to advertisers.

Another example within the same nature is the latest case of beer Amstel where among others the actors mention the phrase "Kaᄉó ка入окаípı phrase which in Albanian language would go more like« "Pushime të mbara"; "Nice vacation" and not:"Verë të mbarë"; "Nice summer "as the interpreter favors.

In the context of internationalization there are many communication agencies that deal with advertising campaigns, a process that turns out to be very difficult because it comes to translations loaded with cultural references. For example

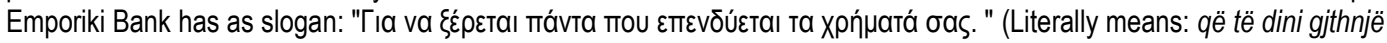
se ku të investoni paratë tuaja; always aware where to invest your money) advertisement that comes into Albanian as: "Tek ne paratë tuaja janë të sigurta"; "With us your money is safe. "It is here where the impact of the effects of time materializes since at the period that this advertisement appeared the country needed a reliably higher trust in banking, after the negative effects of the Ponzi schemes of 1997, while in Greece the concept banking remains focused on investment hiding under the idea of depositing money in the bank.

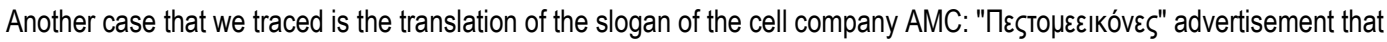
into Albanian has come: "Thuaje me ikona"; "Say it with icons", while it may very well be expressed with: "Thuaje me figura"; "Say it with figures" maintaining the standard of the Albanian language. (The advertisement case Dr. Zlango)

Advertising is today unanimously recognized as a process creation cultural forms by itself and as one of the most powerful means transmitting social and identity images to our societies (Soulages, 1994, pg. 55).

It is known that the translation is often associated with problems of transposition or modulation, in grammar, but more in the lexical field. Beyond the linguistic aspects, in the field of advertising translation notes the close relations of human beings with its physical and metaphysical environment, and therefore can not be separated from the sociocultural context. Without questioning the usefulness of the translation, can we say that it means transferring a similar meaning through languages and cultures changes?

Fedorov $(1953$, p. 22) states that to translate, we should recognize languages, but the difficulty lies in the fact that translating literature is a literary operation, translating verses is a poetry operation but translating a film as well as other cases, it is a sui generis operation.

If it is accepted that the translation is a reinterpretation of the original text, then a rewrite and as a result a creative activity, he cannot be reduced to a linguistic exercise. 
In the case of literary translation, for example the case is not just to switch from one language to another, but to establish a bridge between cultures, very different from each other. Difficulties of translation in this case are the one hand linguistic, stylistic turn but primarily of sociolinguistics. Each advertising translation requires a message that is given in a particular language, transformed in order to be understood by a reader who does not know this language.

In this case the reader does not recognize the culture in question. And what happens with the realities outside the language described by one author and do not exist in the language of the interpreter? Should transposition must be made from a reference system to another, to the detriment of the authentic sociocultural content? Should we preferably translate the slogan of the target language literally to the maximum, the based on the source slogan so that the translation complies as much as possible with the tradition and culture of the source language, but with the risk that this text is not very easy accessible?

Barriers to translators are first and foremost of the semantical type. Those problems become even more acute when there is a large cultural gap between the source text and potential reader of the target language. Mounie writes: " to translate a written text into a foreign language, two conditions are necessary, to know the language and to know the civilization of the source language (life, culture, ethnography)(1976, p. 44)

Communication exchanges may constitute an interpretation problem because of the notions that contain connotation. At the level of translation, connotation (as levels of language) has to do not only with stylistics but also broader aspects such as the sociolinguistics ones.

The author Lederer has formulated several procedures that must be used to succeed in translating the cultural elements:

\section{Adaptation is seen as the first element.}

Differences in legal systems constitute a major obstacle for transcoding; text translator overcomes this difficulty by considering the context and purpose of his translation.

Example: She works for a law firm from 9 to 5.

We found among translations the variant "cabinets juridiques" (legal room), but most of the translators seems to prefer to translate this word "law firm" as lawyer office or room. Certainly a judicial is not a lawyer; but to know somehow the United States, the frequency of intervention of a law firm in the US reality are so frequent, that the translation has considered these cultural realities choosing "cabinet d'avocats".

\section{The transformation (conversion)}

A plate has its composition, it is packed in a certain way and has a social function: a famous plate or served at a feast. The translator recognizes these attributions and tries to clarify as much as possible.

Example: frankly we're all getting a little tired of fried beans.

Fried beans is a well- known dish in South America as the hamburger in North American or steak in France. It is about bean puree stirred in butter or oil and that's serve as sides to all dishes. " So fried" it's not about the deep fry as well as " beans" do not necessary comply with the beans, Albanians are used to: the white beans. They are small black or red beans. Given the large number of restaurants that offer this dish in the USA, the American reader distinguishes in the words "fried beans" a plate that the Albanian reader does not recognize and the translation - "fried beans" would not be proper. Thus we translate "haricots rouges"- "fasule të kuqe"- " red beans" or "haricots noirs"- "fasule të zeza"- "black beans", to respect a part of the exoticism of this dish.

\section{Clear formulation}

Names have the function to identify individuals and category. Those which identify individuals keep the form in a very natural way in the translation. Those identifying categories are being accompanied by their identification.

Example: I couldn't work if it weren't for her, and the fact the Safeway stays open until nine.

Many interpreters have given the variant "supermarket Safeway" to transfer the same information to the Albanian readers. The principle of clear formulation is essential in translation. At the implicit-explicit rapport that exists in each text, the author 
assumes and presents to his reader an amount of information that the interpreter also hasbut that the foreign reader does not fully know or not know at all. A good interpreter skillfully modifies the implicit-explicit rapport from the source to achieve a new implicit-explicit balance in the target language.

The ethnocentrism element is also very important.

It often happens that the translator replaces its culture facts with those mentioned in the text; it makes it more natural.

One example in Greece is the supermarket Mapıvómou^os

In Greece, this is a well- known and widespread supermarket, and in order to translate it into Albanian we have to adopt to a similar one e. g. Euromax.

Using this procedure, minimizing the differences between the source culture and that of the reader, the interpreter requires undoubtedly from the reader to accept its text foreign features could make it even incomprehensible. By doing this, it deletes the original cultural uniqueness and transmits false information. This procedure is also called "naturalization".

A good translator tries not to naturalize the culture of the source language, as well as not to neglect what it should be explained or it have to be understood.

The above-mentioned examples have shown that "the cultural transfer" consists in the fact that it brings knowledge of a world that is not his to the foreign reader. This knowledge does not fully cover the distance between the two worlds, but leaves half open a window into the source culture. To do this the translator preserves the source reference in order to transmit it in understandable forms.

Bringing cultures closer through translation is not certainly done by a single word or by a single slogan. You need to have a variety of slogans translated in order to establish progressively an image where you can avoid prejudices and bring civilizations together, a main goal in the field of advertising and its translation.

\section{Bibliography}

[1] CHUQUET, H. \& M. PAILLARD(1989): Approches linguistiques des problèmes de traduction, Ophrys, Edition revisée.

[2] FEDOROV. A (1953) Introduction à la théorie de la traduction, Moscou.

[3] JACOBSON R (1963) Essai de linguistique generale, Paris, Minuit

[4] MOUNIN G (1976) Linguistique et traduction, Bruxelles

[5] SOULAGES J. C (1994): «Les imaginaires socioculturels et le discours publicitaire» in Le Français dans le Monde, Médias: Faits et effets.

[6] CHARAUDEAU P., (1982): «Eléments de sémiolinguistique d'une théorie du langage à une analyse du discours» in Connexions, n³8, Langage en situation, EPI, Paris, 1982.

[7] Marianne Lederer La traduction aujourd hui,1994, Hachette 